\title{
Historical and Cultural Perspectives on Integrative Medicine
}

\author{
Richard P. Petri, Jr., MD, FAAPMR, FAAIM, COL MC, \\ Roxana E. Delgado, $\mathrm{PhD}, \mathrm{MS},{ }^{2}$ and Kimberly McConnell, $\mathrm{EdD}^{3}$
}

\begin{abstract}
Background: The field of medicine dates back to ancient times. Early practices were adopted by subsequent societies. Cultures had significant influences over many aspects of life. Globally, there is a health care crisis of inadequate delivery and less-than-optimal outcomes despite all the advancements and evidence provided by modern biomedicine. North Atlantic Treaty Organization countries represent diverse cultures and societal experiences and, collectively, may offer new perspectives in the evolution of health care delivery.

Objective: A retrospective review of the influences of ancient practices and cultures is provided. This can serve as a foundation for a prospective discussion about integrating the various current systems into a better paradigm of health care.

Methods: This article discusses the impact of historical and cultural perspectives on medicine in general and on specifically integrative medicine (IM). The origins of some IM modalities are highlighted.

Conclusions: History reveals that new medical paradigms were a blending of old traditions with new innovations. Changes occurred because society questioned old methods. Today the situation is not different. The field of IM is evolving as a result.
\end{abstract}

Key Words: Historical Perspective, Integrative Medicine, Complementary and Alternative, Culture, Society, NATO

\section{INTRODUCTION}

A BUREAUCRACY IS OFTEN A BARRIER to an institution's adherence to its original mission and purpose. Today's health care system seems to have fallen victim to its systems of management, thereby diluting the intended goal of caring for patients. Patients are responding to a perceived system of depersonalized algorithmic care and limited contact with providers. This is a system in which technology has often replaced human interaction. Thus, patients have sought new means of health care to meet their needs, expectations, beliefs, and values. Patients in Military populations have done the same as civilian patients. ${ }^{1-6}$

Health care systems are deeply embedded in civilization's economic, religious, and societal cultures. Historical accounts are often passed down, thus permitting infusion of previous systems to be adopted into current systems. However, this adoption occurs often with reluctance. Furthermore, it must be remembered that historical accounts are only related stories from personal perspectives.

\footnotetext{
${ }^{1}$ United States Army, Chairman, NATO HFM-195 Task Force, Integrative Medicine Interventions for Military Personnel, El Paso, TX.

${ }^{2}$ Senior Research Associate, Samueli Institute, Alexandria, VA.

${ }^{3}$ Senior Research Associate, Samueli Institute, San Antonio Military Medical Center, San Antonio, TX.

This article was prepared as part of the work product of NATO Science and Technology Organization, Task Force, Human Factors and Medicine (STO-TR-HFM) 195, Integrative Medicine Interventions for Military Personnel.

*The opinions and assertions contained herein are the private views of the author and are not to be construed as official or as reflecting the views of the United States Army or Air Force Medical Corps, the Army or Air Force at large, or the Department of Defense. The authors indicate that they do not have any conflicts of interests.
} 
A perspective can often be clouded by an agenda. Nonetheless, history is the binding factor. Historical accounts document the transition from the past to the future.

Globally, there is a health care crisis of inadequate delivery and less-than-optimal outcomes despite all the advancements and evidence of modern biomedicine. Thus, a retrospective review of the influences of ancient practices and cultures is necessary. This article can serve as a foundation for a prospective discussion on integrating the various current systems into a better paradigm of health care.

\section{HISTORICAL PERSPECTIVES}

The origins of medicine are deeply rooted in a civilization's culture and religious beliefs. Often, educated priests practiced medicine. Early medicine dealt with experiences, observations, and reflections of the self and one's surroundings. There was no separation of mind and body. In the 1600s, Rene Descartes (cited by Chiappelli et al.), in an attempt to protect the spirit from science, separated the mind from the body. ${ }^{7}$ This set the stage for the current state of the Western style mind-body split and evidence-based medicine versus nonconventional or complementary medicine. This was the beginning of the reductionistic movement with the goal of understanding the parts to gain a larger understanding of the whole. Only within the past few decades, has there been an attempt to reunite the medical systems of curing (technological, microscopic, and disease-based) with healing (nonphysical, holistic, and relationship-based). The following is a brief history of important and relevant world cultures that have contributed to the field of medicine, conventionally and unconventionally.

\section{Mesopotamia and Egypt: 3100 BC}

It is believed that the oldest civilizations were in the areas of present-day Egypt and Iraq (Mesopotamia). Given that medicine is so often culturally based, it undoubtedly follows that the first medicine came from these civilizations. Thoth (Fig. 1) was an Egyptian god who was the inventor of art in general. He is believed to have been the author of the oldest Egyptian medical work with the contents engraved upon pillars of stone. His words formed a part of the Hermetic Books (cited by Bass) used by the physicians of the day. ${ }^{8}$ Interestingly, Egyptian medicine was divided into two degrees. The Science of higher degree consisted of conjurations, dissolving the charms of gods by prayer, and interpretations of revelations received by the sick person during incubations in temples. The highest class of priest performed as the physicians of the higher Science. The Science of the lower degree was "ordinary medical practice" and was practiced by the lowest grade of priests. They studied anatomy, pathology, pharmacology, ophthalmology, and gynecology. It is interesting, therefore, that the higher order of Science dealt with areas, which today some people have called "Voodoo" medicine.

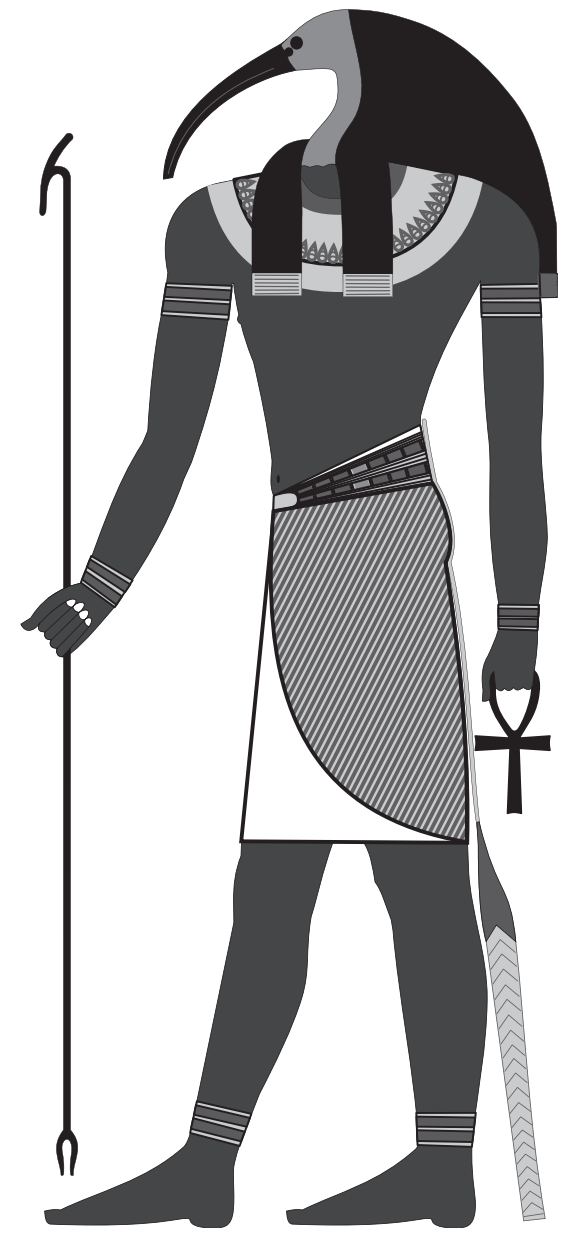

FIG. 1. Thoth, ancient Egyptian god often depicted as an ibisheaded man. Based on New Kingdom tomb painting. By Jeff Dahl (Own work). Licensed under Creative Commons (CCBY).

The Egyptians developed a system of specialties described as "physicians in Egypt for each part of the body." In fact, there were priestly physicians who followed the army and were employed by the state. In Outlines of the History of Medicine and the Medical Profession, it is stated: "[T]his specialism is per se an evidence of a civilization of high development, indeed of one tending towards its downfall, and in Egypt it attained a perfection which our own system, with all its completeness, has not yet reached." 8 Current day Western biomedicine continues to pursue scientific inquiry with specialization and microscopic divisions. Thus, could our system of intense specialization be a portent of our health care system's downfall if it is continued without deviation?

Aromatherapy began in ancient Egypt. The Egyptians excelled in the use of oils, salts, alabasters, and creams for all kinds of diseases and for preservation of the dead. ${ }^{9} \mathrm{Ne}-$ fertum was the god of perfumes, incense, and fragrant oils. His mother, Sekmer, was the goddess of healing and alchemical distillation. The use of fragrance was the means of communication between the gods and humanity, offering health to the living and assisting the dead in the next life. ${ }^{10}$ 
The Egyptians believed that the body could heal itself and used reflexology to restore balance and the natural equilibrium. $^{9}$

\section{India in $2500 \mathrm{BC}$}

Unlike many civilizations that imported systems of other outside cultures, Indian medicine was derived in India and had interwoven systems of other cultures, predominately Greek, as part of India's own system, but this interweaving occurred only at a later time period. ${ }^{8}$

The ancient Indians wrote about medicine in their sacred books, known as the Vedas (Fig. 2). The Vedas are believed to be of divine origin and were passed down through oral traditions until the sixteenth century AD. One of the Vedas, the Atharvaveda, is a collection of spells, hymns, and incantations for magical curing of diseases, and is thought to have been the origin of the traditional Indian medicine system known as Ayurveda. ${ }^{8}$ Ayurveda is based on the concepts of longevity and the nourishment of life. ${ }^{11}$ Later

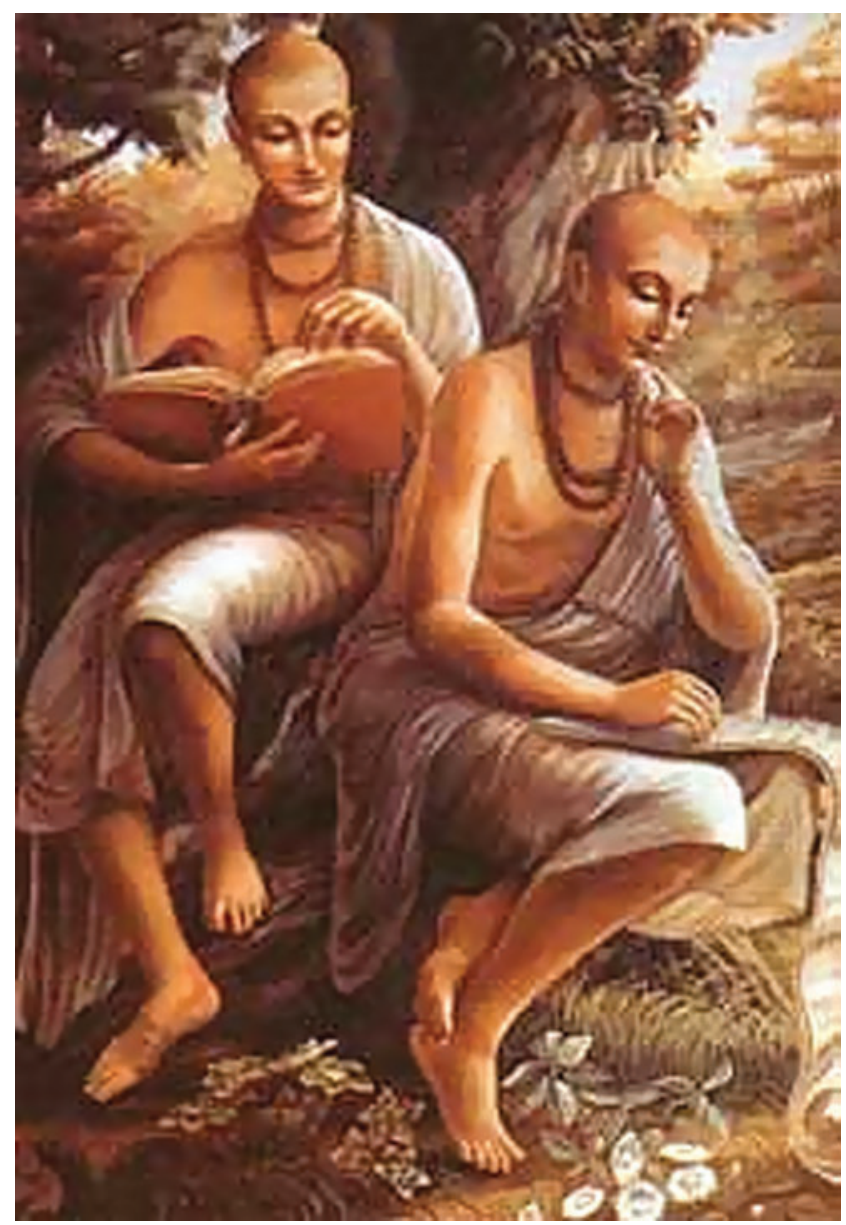

FIG. 2. The Recording of the Vedas in Ancient India. This is the front cover of the book "The Nectar of Instruction $1^{\text {st }}$ edition" by A.C. Bhaktivedanta Swami, Founder of the International Society of Krishna Consciousness. Artwork reprinted with permission from The Bhaktivedanta Book Trust International, Inc. commentaries on the Vedas, known as the Brahmanas and the Upanishads, explained these texts and speculated about the nature of the universe as well as the human condition. ${ }^{12}$

Yoga-a term derived from the Sanskrit word yug — was a theological practice that was believed to lead to the unification of self with the Divine. Yoga's origins are believed to date back to pre-Vedic traditions. Yoga is a practice that was considered to be given directly from God. The foundation is based on the suppression of all activities so that one can identify and separate the self from the body, mind, and will. In doing so, one attains spiritual liberation. ${ }^{9}$ Yoga, when practiced in the true Indian tradition, is more than a physical exercise program. It has a meditative and spiritual core, and offers a meaningful purpose for life and living.

Buddhism originated in India in the sixth century BC under the teachings of the Buddha. These teachings were in protest of the strict stratification of the Hindu society as well as the religious control of the Brahmanic priests. Buddha emphasized universal love, service, and peace of mind brought about through abandonment of desire. ${ }^{12}$

Unani medicine, a lesser-known India medicine subtype, is based on the theory of the Four Elements of the human body (i.e., Fire, Water, Earth and Air). Different fluids represent these elements. When the fluids are balanced, there is health; when the fluids are imbalanced there is illness. ${ }^{13}$

An esoteric form of alternative medicine described in Indian literature is the healing practice of Uropathy. This is a method of healing with the use of one's own urine. It is referred to as Shivambu or "holy liquid." In the Tantric Yoga culture, it is termed Amroli. Amroli is derived from the word Amar, which means undying. Hence, Amroli was a spiritual practice that was beneficial to the mind, body, and spirit for the attainment of immortality. ${ }^{14}$ It is believed that hundreds of ailments can be cured by urine therapy. ${ }^{15}$ Uropathy is not widely practiced today; however, there are World Congresses on the subject, numerous books and articles on this topic.

Finally, Indian medicine was weakest in the area of anatomy because of a prohibition against living people having physical contact with dead people.

\section{China in $1600 \mathrm{BC}$}

It is widely believed that Traditional Chinese Medicine (TCM) has a 3000-4000-year history. TCM was embedded in the "philosophy of Confucius who called for the ideal family ties and the promotion of social and ethical standards of societies." The oldest Chinese medical texts are thought to be on herbal medicine. The Yellow Emperor, Huang Di, wrote about acupuncture, the concept of Yin and Yang, and the Five Phases in his book, The Yellow Emperor's Inner Classic (Huang Di Nei Jing; cited by Ergil). ${ }^{16}$

TCM spread across Asia throughout the centuries and came eventually into the Western world in the sixteenth to the twentieth centuries AD. However, only fragments of 
TCM are practiced in the West. Nonetheless, TCM has influenced the delivery of Western-style health care. Likewise, TCM has not remained stagnant in practice either. Concepts have come and gone and returned over time, depending on current societal perspectives and political environments. Unlike the West, in which an incomplete theory or unacceptable concept is rejected and then disappears, TCM may reject a theory but it does not disappear. It may fade in practice, but it continues to exist and may return at a later time. In the West, it is often thought that something is "either this or that." However, in TCM, opposing theories can exist. An example of this is the concept of Yin and Yang. Although Yin and Yang oppose each other, they are also complementary to each other (Fig. 3). ${ }^{16}$

TCM is the overreaching umbrella for many disciplines. Acupuncture is one of those disciplines. The mythological basis of acupuncture suggests that the Chinese speared human bodies to rid towns and villages of demons and evil spirits. Acupuncture evolved over time. The practice of acupuncture was influenced significantly by the reorganized text of the Yellow Emperor's Inner Classic (cited by Ergil) and other earlier texts into the text Systematic Text of Acupuncture (and moxibustion; cited by Ergil) circa the third century CE. ${ }^{16}$

TCM was primarily a system for the Chinese elite rather than for the population of the entire nation. Much of the country's population was illiterate, and, as such, little is known about the population. It is believed that the illiterate people's traditions were based on folk superstitions, legends, and survival. ${ }^{16}$

The true history of acupuncture may never be known. Despite the fact that classical texts on acupuncture exist, these texts often do not describe the clinical practices. The theories and concepts of Chinese acupuncture do not always translate well and, therefore, the meaning and significance of both have been lost.

Throughout history, TCM and acupuncture have been subject to religious, cultural, and political pressures. During the late nineteenth and early twentieth centuries, TCM was politically under attack to make way for a new and more modern China. In 1822, acupuncture was banned from the

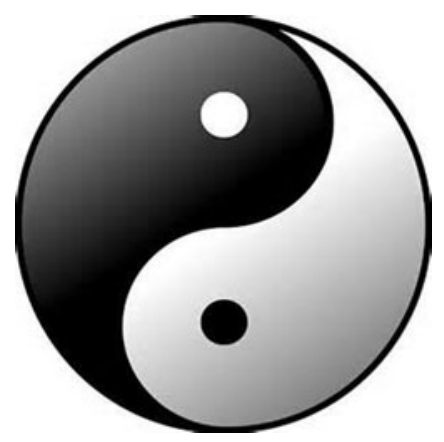

FIG. 3. Yin Yang Symbol. By DonkeyHotey (Own work). Licensed under Creative Commons (CCBY).
Imperial Medical Academy after nearly 1200 years of basic Imperial medical education. ${ }^{17}$ There was a significant movement to move toward scientifically based medicine. Many of the scientifically trained physicians were concentrated in only three major cities, leaving voids in the other urban and in all rural areas. Thus, the ban undercut the health care system of the common people, because much of their care was solely based one TCM.

Only after 1954, did acupuncture become reinvented. Chairman Mao ordered all Western medicine practitioners to study acupuncture. This resulted in organization of the TCM practitioners to provide health care. However, it is not clear if this new acupuncture actually resembled the true acupuncture of the millennia before.

Other TCM practices include movement of invisible energies (Feng Shui), dietary/herbal therapies ("we are what we eat"), and kinesiology (t'ai chi, Qigong). This system of exercise was known as the "Frolics of Five Animals.", 18 Similar to Indian medicine, TCM supports the holistic view of treating the mind, body, and spirit, and the individual's experience of the disease. ${ }^{9}$

TCM has been practiced in the United States since the mid nineteenth century. Bache was the first American physician to use acupuncture in his practice (in 1826). In 1901, Ah Fong Chuck was the first licensed practitioner of TCM. Acupuncture gained greater popularity after James Reston, a reporter for The New York Times, underwent an emergency appendectomy while he was in China with former President Richard Nixon in $1971 .^{19}$

\section{Greece in 800 BC}

The ancient traditions of Greece have provided the foundations of Western philosophy, science, and medicine. ${ }^{20}$ However, history shows that the Greeks went to Egypt for their medical training. Greek medicine was comprised of magic and legendary beliefs. Like what occurred in preceding cultures, Greek medicine was strongly embedded with priests, seers, and god figures. Apollo, the most powerful god-physician, would cause epidemics as punishments. Yet, he would also revive and heal wounded people. ${ }^{20}$

Pythagoras, well-known for his mathematical formulas, was the first Greek philosopher interested in medicine. Mathematics influenced the concept of opposite quantities. The balancing of these opposites was important to health and disease. ${ }^{20}$

Hippocrates (Fig. 4) is considered to be the father of Western medicine. He established "medicine as an art, science and a profession of profound value and dignity.",20 Medicine was no longer a part of philosophy. ${ }^{21}$

The life of Hippocrates is not well-documented, and it is argued by some scholars that Hippocrates was not an individual person. Nonetheless, he is credited with the theory of the Four Humors to mirror the earth's four elements. ${ }^{9}$ These humors, with their associated qualities (hot, cold, moist, and 


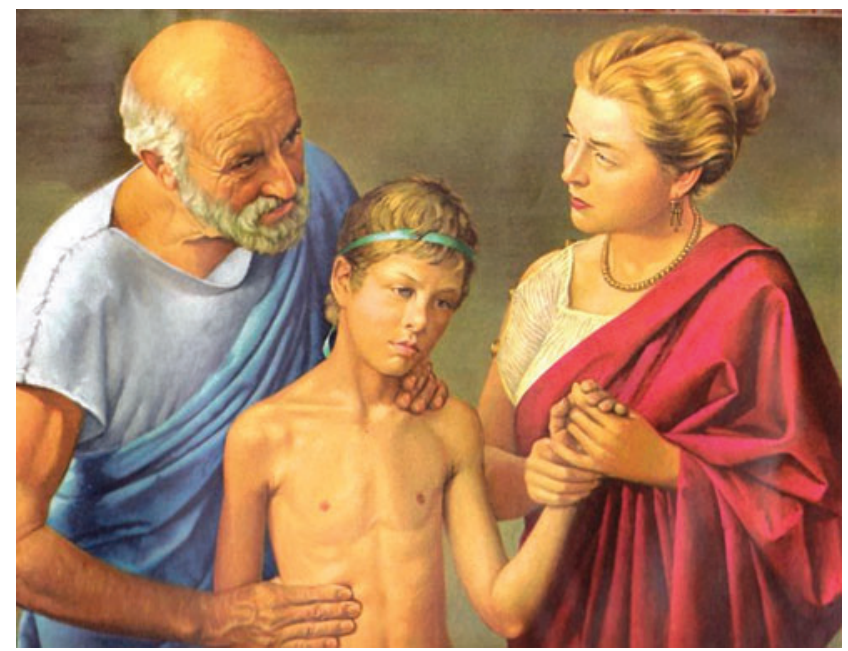

FIG. 4. Hippocrates: Medicine Becomes a Science. Reprinted with permission from Collection of the University of Michigan Health System, Gift of Pfizer, Inc., UMHS.7.

dry), formed the human microcosm, which was reflective of the larger universal macrocosm. Health was achieved through a balance and blending of the humors. Hippocrates believed that dietetics was the basis for the art of healing. Thus, food could be used to achieve health and healing. ${ }^{20}$

Current standard herbal textbooks are based on the herbal medicine book written by the Greek physician Dioscorides (cited by Oumeish). ${ }^{9}$ The term medica comes from the Greek mythological story of Medea, sorcerer of the seventh century and the land Media. Media is the area of current northwestern Iran and southwestern Turkey. The plants of Media were known as "median herbs" and their ointments, medicamentum, the root for our current term medications, could be used to heal or poison. This implied that medications could be used for healing or harming. ${ }^{7}$

\section{Rome in $27 \mathrm{BC}$}

In the early days of Christianity, the system of medicine had a strong overlay of mysticism (Fig. 5). The Christians believed that disease was the result of sinful behaviors and cure was achieved through grace or suffering. Often, the ability to touch a "holy relic" was a promise of healing. Some of the relics noted to have these healing properties included the "finger of the Holy Ghost," rays of the Star which led the Wise Men to the birthplace of Jesus," and a rib of the Word made flesh.",22

Much of Roman medicine was adapted from the Greeks. The Romans improved aromatherapy with their spas, saunas, and baths. ${ }^{9}$ Roman medicine was greatly influenced by the work of the prominent physician Galen. It was believed that imbalance in the four humors led to diseases, a belief that was originated by Hippocrates. After Galen's death, medicine in Rome began to stagnate. There was distrust in the system, which is now considered to be greedy, incompetent, and dishonest. The public sought new means of

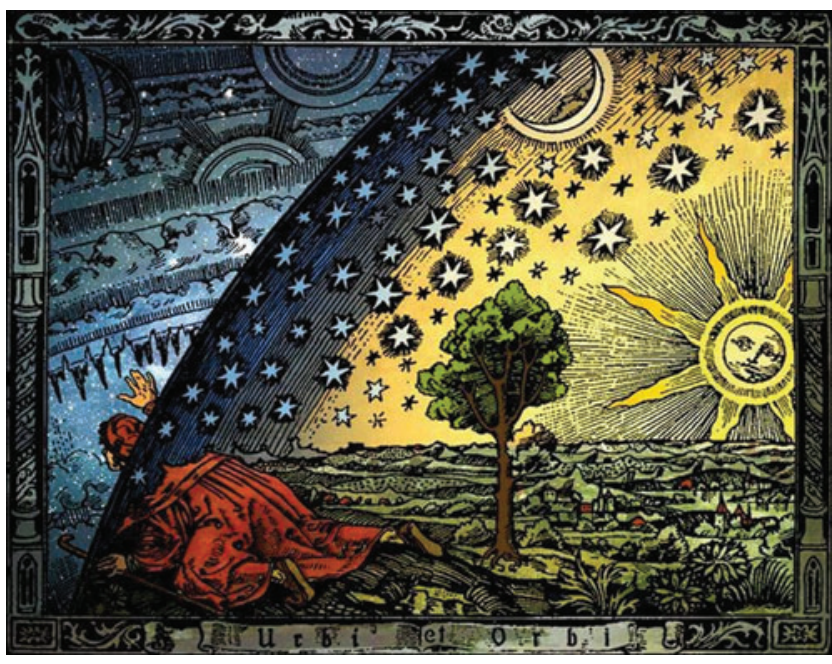

FIG. 5. The Flammarion engraving is a wood engraving by an unknown artist that first appeared in Camille Flammarion's L'atmosphère: météorologie populaire (1888). The image depicts a man crawling under the edge of the sky, depicted as if it were a solid hemisphere, to look at the mysterious Empyrean beyond. The caption translates to "A medieval missionary tells that he has found the point where heaven and Earth meet..." By unknown artist. Source: Wikimedia.org.

treatment from their own gardens, a principle known as Euporista. Books on the subject began to replace physicians. It was believed that nature provided remedies. In the late Roman period, individuals could practice medicine without training. Organized medicine was replaced by supernatural principles and home remedies. ${ }^{23}$ Public beliefs overran scientific principles.

\section{Islamic Golden Age: 622 AD}

During the Islamic Golden Age, Persian physicians contributed to medicine in two phases. The first was a period of translations (750-900 BC). The philosophers, Gerber (721

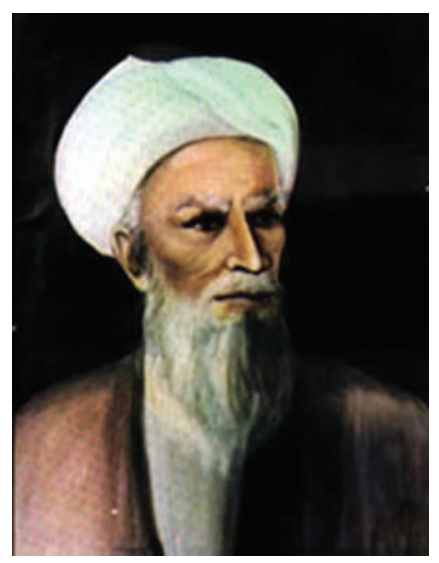

FIG. 6. Muhammed ibn Zakariya al-Razi. Also known as Razis or Rhazes. Persian philosopher and physician. This is a faithful photographic reproduction of a two-dimensional, public domain work of art. Source: Wikimedia.org. 
BC), Al-Kindi (801 BC), Rhazes (865 BC; Fig. 6), Al-Farabi (872 BC), Avicenna (980 BC), and Averroës (1126 AD) had profound effect on the Dark Ages of Europe. The Dark Ages comprised a period of time when there was little advancement in the field of medicine.

The previous civilizations' medical knowledge, especially the Greek knowledge, was preserved, which enabled its passage to Europe upon that region's emergence from the Dark Ages period. ${ }^{22}$ Moir, a Scottish physician states that "medicine is incalculably indebted to the Saracens," [a generic term for Muslim during the later Medieval era] "for the preservation of the Greek writers; as it was only after the return of the French, Italian and English from the Crusades, that these came to be known in Europe, through translations from the Arabic." 24

The second period was a period of observations and expansion. (900-1100 BC). During the time of Mohammed, the culture promoted learning, arts, and sciences for intellectual development. The region established great medical colleges with strict admission guidelines. The schools followed rigorous scientific principles, and understood the use of anesthetics and hygiene. Their ancient materia medica rivals that of Western medical textbooks today. ${ }^{24}$

Arabic medicine was practiced within the context of Islam's system of ethnics. It became known as Prophetic Medicine. It was believed that true medical knowledge came from revelations from the Prophet. ${ }^{23}$ It was supernatural, and esoteric, and filled with unconventional imagery; however, this medicine suited the majority of the people, was inexpensive, and was widely accepted. Arabic medicine was linked to philosophy and tied to numerical and astrological symbolism. Magicoreligious thoughts had significant influences on the system. Some of the practices included fortune telling, exorcisms, inspirations, amulets, healing gems and crystals, charms and spells, and cupping. The physician stressed treating the early symptoms by unconventional means to expose disease early treatable stages. These physicians often used herbals for such treatments. ${ }^{9}$

Although the Arabic physicians copied much from other civilizations, these physicians did expand their knowledge of medicine. They divided medicine into three distinct professions: physic; pharmacy; and surgery. In the areas of aromatics and purgatives, Arabic physicians added their knowledge to botanical and materia medicas extensively. Rhazes wrote the first treatise on the diseases of children. The Arabs raised the dignity of the medical profession from one of a menial calling to a learned profession with examinations and licensing. ${ }^{9,25}$

\section{The Renaissance to the Modern Era}

The emergence of the Dark Ages into that of the Renaissance was largely the result of the Arabic period of translation. The ancient works were brought forward to the modern era through translation into the common language of the time: Latin. This was followed by an expansion in experimental investigation, particularly in dissection of the human body. As a result, human anatomy and neurology had significant advancements. Famous theories and principles were criticized and often debunked. Science began to replace mysticism. New publications spurred excitement and interest. Anatomical dissection theaters flourished, attracting artists, students, and scientists. University medical training began in Salerno and then later in Padua and Bologna, Italy, followed by France and England. However, this training was primarily academic with little clinical experience. Medicine began its descriptive phase. ${ }^{26}$

During the next several centuries, medicine expanded in its scientific knowledge base exponentially. Technological advances contributed and enabled a deeper range of observations, interactions, and interventions. Generalities became specific. Specialization occurred at an unprecedented rate and to the point that there was subspecialization for treating minute portions of organ systems. As such, medicine became compartmentalized with some people stating that medicine had become depersonalized as well.

This trend was advanced and complemented by economic, political, and military powers of the times. Powerful cultures colonized older, less-powerful cultures, so that Western medicine became global.

\section{Shamans, Medicine Men ${ }^{\dagger}$ and Curanderos}

The term shaman comes from the Tungas language of Central Siberia. A shaman is an individual who enters altered states of consciousness in order to acquire knowledge and power and to help patients. ${ }^{27}$ Shamans use drums to call upon spirit allies. ${ }^{28}$ The repetitive sound of the drum facilitates the trance states in shamanistic practices. These drums are likened to a canoe or horse that transports the shaman into "the Lowerworld or Upperworld." ${ }^{29}$ Shamanism cannot be learned, but rather, shamans are born into the life. ${ }^{28}$ This calling is that of a healer. Shamanism represents "the most widespread and ancient methodological system of healing known to humanity." 29

During the practice of shamanism, both the shaman and the patient travel on the journey together. There is a deep level of connectedness between the two; something that is often lacking in today's doctor-patient relationship. Despite the significant differences in the cultures and the separation by distances, shamanistic practices across the world are similar. Thus, "the basic uniformity of shamanic methods suggests that, through trial and error, people arrived at the same conclusions. ${ }^{30}$ In many regions of the world, the shaman is seen as "the great specialist of the human soul: he alone 'sees' it, for he knows its 'form' and its destiny.",31 Names such as witch, magic man, witchdoctor, seer,

$\dagger$ In many shamanistic traditions, the shamans are typically men rather than being men and women. 
sorcerer and medicine man have been used interchangeably for shamans. ${ }^{27}$

Shamanistic practices are very prevalent in traditional Native American practices of today. These shamans are often known as medicine men. Most of the pre-Columbian practices were not recorded or did not survive. The early European settlers provided the earliest accounts. Native Americans were not a homogenous population and, as such, neither were their practices. However, a common thread of the medicine men was that all aspects of life were intimately connected to good health and well-being. Life was a circle, and the healing included all aspects of an individual's life, family, and community. The medicine man practiced a highly advanced medicine that was effective for combating diseases that were common to their day. Some herbal-based treatments included echinacea (Echinacea spp.), ephedrine (Ephedraceae spp.) and cacao (Theobroma cacao) which are widely used in contemporary medicine and society. ${ }^{32}$

Cacao was cultivated in the Mesoamerica region (current day central Mexico) dating back to 1900 BC. Cacao was so revered, that "all subjects in service to the Aztec emperor were required to bring several bags of cacao in tribute." 33 The Aztecs mixed cacao with other ingredients such as chili (Capsicum annuum), black pepper (Piper nigrum), cornmeal or plantains to make the traditional drink chocolatl. Sugar was not added until 1528, when Columbus introduced cacao to the Spaniards. Cacao was used for a multitude of illnesses (weight gain, invigoration of the nervous system of the apathetic, exhausted or weak, improvement of digestion and bowel function and stimulation of kidney) as well as a flavoring for other medicines, especially those for children. In addition to the cacao bean, the leaves, flowers, bark and oil had medicinal properties that were used to treat burns, cuts and skin irritations. ${ }^{33}$

The term curanderismo describes a broad healing tradition of Latin America. The word is derived from the Spanish verb curar, which means "to heal." There are seven pillars or cultural and historical roots of curanderismo. These represent the blending of ancient civilizations with the native populations of Latin America. The construct of curanderismo is based on the duality of natural and supernatural causes. Natural causes can be treated with herbal remedies, whereas the supernatural causes require treatment only by the supernatural manipulations performed by curanderos. Supernatural causes of illness are the result of either espiritos malos (evil spirits) or brujos. Brujos are individuals who practice maligning magic. The supernatural manipulations consist of several types of rituals such as sweeping, incensing, or conjuring, which lead to removal of negative forces. Curanderismo practices often provide better healing for chronic mental health conditions as well as for alcohol and drug addiction than interventions of Western psychiatry and psychology. ${ }^{34}$

The healing practices of curanderos are culturally meaningful to their societies. This is a must for any health care system to be effective. In addition, curanderismo blends worldwide healing traditions, both ancient and contemporary, for a true integration of different approaches. ${ }^{34}$ Thus, lessons should be learned as the new paradigm of integrative medicine (IM) is developed.

\section{DISCUSSION}

Prior cultures have shaped the present day to form the foundation of the future. Societies' cultures are influenced by the religious and political classes of the time. The health care of a given time period is a reflection of those influences. Thus, the struggles of the present evolution in health care is not unlike past turmoil, power grasps, and reluctance to "let go of the status quo." Of all the great societies, only the Indian and Chinese medical systems have endured as health care systems. In addition, it is not clear how well history has recorded the true philosophies of each.

Today, priests and clerics do not control health care, unlike much of the ancient times. In fact, it is often not permitted. The incorporation of religious practices within Military cultures is often met with skepticism and resistance. However, it seems that spirituality is more acceptable. The Human Performance Resource Center, a U.S. Department of Defense initiative under the Force Health Protection and Readiness Program developed the Total Force Fitness (TFF) program. It is a framework for building and maintaining health, readiness, and performance. The TFF program views health, wellness, and resilience as a holistic concept wherein optimal performance requires connections among mind, body, spirit, and family/social relationships. Information about the TFF program was published in a special issue of Military Medicine ${ }^{35}$ with a chapter devoted to solely to spiritual fitness. ${ }^{36}$ In addition, there is a chapter within this current North Atlantic Treaty Organization (NATO) Special Issue of Medical Acupuncture describing a systematic review of spirituality/ religiosity, and what context this can be applied to Soldiers in the course of healing (pp. 360-366).

Regarding an area related to this concept, there is current controversy regarding implementing yoga into some Military health care systems because "it represents a religion." Although yoga has a religious foundation, "Western style" yoga is no more a religious practice than many fitness classes, (Pilates, zumba, aerobics) offered at most gyms. When yoga is practiced in the true Indian tradition this yoga is more concerned with spirituality than with religiosity.

Thus, utilization of religious practices as part of health care systems is not acceptable; however, it seems that spirituality may be a necessary component of an individual's healing journey.

Politics has played an enormous role in shaping health care in the past. Today, this situation is not different. Current debates regarding acupuncture are similar to those nearly 2 centuries ago. Most recently, in 1928, The China's National 
Health Council issued a resolution banning acupuncture. It is interesting how the tone of the resolution is similar to the arguments used in opposition to IM today. In the Resolution for Abolishing the Native Practice Proposal, it is stated:

The medicine of today has advanced from the curative to the preventive stage, individual to collective medicine, personal to community emphasis. Modern public health service is based entirely on scientific medical knowledge with the corresponding political backing. The old-style medicine of China adopts the doctrines which are pure speculations having not a grain of truth. The diagnosis depends wholly on the signs of the pulse. Such absurd theories are deceptive to one self [sic] and to others. They may be classified in the same category as astrology. Since fundamentally they do not know diagnosis, it is impossible for them to certify the causes of death, classify diseases, combat epidemics. The evolution of civilization is from the supernatural to the human, from the philosophical to the practical. Now while the Government is trying to combat superstition and abolish idols so as to bring the people's thoughts to proper scientific channels, the old-style physicians, on the other hand, are daily deceiving the masses with their faith healing. While the Government is educating the public as to the benefits of cleanliness and disinfection and the fact that germs are the root of most diseases, the old-style physicians are broadcasting such theories as when one catches cold in winter, typhoid will appear in spring; when one suffers from the heat in summer, malaria will come in autumn. These reactionary thoughts are the greatest hindrance to scientific progress. (Cited by Wong and $\mathrm{Wu})^{37}$

Thus today, with improved research techniques and acceptance of new/old methods, integrative medicine modalities, such as acupuncture, meditation, and yoga, to list only a few, are being investigated and incorporated in global health care systems.

\section{CONCLUSIONS}

Culture is complex and multifactorial. It influences all aspects of society. Likewise, the society influences all aspects of culture. However, too often, culture has been shaped/decided by the powerful classes of their times. This applied to the field of medicine as well. Only over the past several decades has there been a renewed grassroots effort to change the course of medicine. Society is affecting the rule of the "deciding" class. There is a push to diminish the role of technology in patient care and return medicine to a more humanistic approach to healing and health. However, this movement is nothing new. It has been repeated many times since ancient cultures. As with all things, paradigms evolve, resulting in changes in philosophy, terminology, and policy. As with all things, as understood by history, more changes will come. Thus the culture, with its impact on the present as well as the future, will be defined.

\section{RECOMMENDATIONS}

Medical health care systems of the world are constantly changing. They must do so. As such, it is imperative to study the cultures and societies that laid the foundations of medicine in the past. Lessons can be learned and mistakes can be avoided. However, the greatest advantage that history provides is the ability to take knowledge from the past and weave it into today's knowledge to improve future knowledge. The collective experiences of the NATO countries with their diverse cultures can facilitate this, and this resource should be utilized.

\section{AUTHOR DISCLOSURE STATEMENT}

COL Richard Petri, MC (MD), is an Active Duty Service Member in the United States Army and was appointed to the NATO panel HFM-195 ("Integrative Medicine Interventions for Military Personnel") as a technical team member. He was selected to the Chair of the panel in September 2013. Resources from the United States Army supported the travel expenses to the first four team meetings. The fifth meeting lodging expenses were partially supported by a grant from the Geneva Foundation. The remaining expenses were paid through personal resources. No competing financial conflicts exist. Roxana E. Delgado, PhD, MS, is a health scientist at Samueli Institute, a health and wellness research non-profit organization. Resources from Samueli Institute were used to support the author's time and effort to write this chapter. No competing financial conflicts exist. Kimberly McConnell, EdD, is a senior research associate at Samueli Institute, a health and wellness research non-profit organization, and a research associate of the DoD (United States Army) research grant to Samueli Institute, which funded some of the preliminary work of the NATO panel HFM-195. Resources from Samueli Institute were used to support the author's time and effort to write this chapter. No competing financial conflicts exist.

\section{REFERENCES}

1. McPherson F, Schwenka MA. Use of complementary and alternative therapies among active duty soldiers, military retirees, and family members at a military hospital. Mil Med. 2004;169(5):354-357.

2. George S, Jackson JL, Passamonti M. Complementary and alternative medicine in a military primary care clinic: A 5year cohort study. Mil Med. 2011;176(6):685-688.

3. Kroesen K, Baldwin CM, Brooks AJ, Bell IR. US Military veterans' perceptions of the conventional medical care system and their use of complementary and alternative medicine. Fam Pract. 2002;19(1):57-64.

4. White MR, Jacobson IG, Smith B, et al. Health care utilization among complementary and alternative medicine users in a large military cohort. BMC Complement Altern Med. 2011;11:27. 
5. Smith TC, Ryan MA, Smith B, et al. Complementary and alternative medicine use among US Navy and Marine Corps personnel. BMC Complement Altern Med. 2007;7:16.

6. Goertz C, Marriott BP, Finch MD, et al. Military report more complementary and alternative medicine use than civilians. $J$ Altern Complement Med. 2013;19(6):509-517.

7. Chiappelli F, Prolo P, Cajulis OS. Evidence-based research in complementary and alternative medicine I: History. Evid Based Complement Alternat Med. 2005;2(4):453-458.

8. Baas JH. The medical culture of those nations whose development in medicine is either already closed or is stationary (or not independent): The history of the most ancient medicine and the medicine of primeval people. In: Baas JH. Author. Outlines of the History of Medicine and the Medical Profession. New York: J.H.Vail \& Co.; 1889:13-78.

9. Oumeish OY. The philosophical, cultural and historical aspects of complementary, alternative, unconventional and integrative medicine in the Old World. Arch Dermatol. 1998;134(11): 1373-1386.

10. Hoffman CJ. Aromatherapy. In: Micozzi MS, ed. Fundamentals of Complementary and Integrative Medicine, $3 r d$ ed. St Louis: Saunders Elsevier; 2006:209-228

11. Zysk KG. Medicine and Buddhist monasticism. In: Asceticism and Healing in Ancient India: Medicine in the Buddhist Monastery, rev. ed. Oxford, UK: Oxford University Press; 1988:38-49.

12. Magner LN. The great medical traditions of India and China. In: A History of Medicine. New York: Marcel Dekker; 1992:37-62.

13. Rahman HS. Arab medicine during the ages. Stud Hist Med Sci. 1996;XIV(1-2):1-39.

14. Thakkar GK. History of Shivambu. In: Shivambu Gita: Which Can Bestow Upon You New Life. Mumbai: Shree Nagesh Mudranalaya; 1996:41-47.

15. van der Kroon C. The Golden Fountain: The Complete Guide to Urine Therapy. Mesa, AZ: Wishland Publishing, Inc.; 1996.

16. Ergil K. Traditional Medicine of China and East Asia. In: Micozzi Marc S, ed. Fundamentals of Complementary and Integrative Medicine, 5th ed. St. Louis: Saunders Elsevier; 2015:477-507.

17. Qiu XI. Chinese Acupuncture and Moxibustion. New York: Churchill Livingstone; 1993.

18. Hong, FF. History of medicine in China when medicine took an alternative path. MJM 2004;8:79-84.

19. Ergil, K. Chinese medicine. In: Micozzi MS, ed. Fundamentals of Complementary and Integrative Medicine, 3rd ed. St. Louis: Elsevier Saunders; 2006:393-417.

20. Magner LN. Greco-Roman Medicine. In: A History of Medicine. New York: Marcel Dekker; 1992:63-80.

21. Grammaticos PC, Diamantis A. Useful known and unknown views of the father of modern medicine, Hippocrates, and his teacher Democritus. Hell J Nucl Med. 2008;11(1):2-4.

22. Geiger R. Homeopathy among the ancient Hindus and Arabians. J Am Inst Homeopath. 1945:38:387.
23. Prioreschi P. Alternative medicine in ancient and medieval history. Med Hypotheses. 2000;55(4):319-325.

24. Moir DM. Avenzoar-Averrhoes and extinction of the Arabian school. In: Outlines of Ancient History of Medicine. Edinburgh: Neill and Co. Printers; 1831:264-278.

25. Lu GD, Needham J. China and the origin of examination in medicine. Proc R Soc Med. 1963;56(2):63-70.

26. Rhodes P. An Outline History of Medicine. Oxford, UK: Butterworth-Heinemann; 1985.

27. Harner M. The shamanic journey: Introduction. In: The Way of the Shaman, 3rd ed. San Francisco: Harper \& Row; 1990:50-80.

28. Micozzi AM, Micozzi MS. Magico-religious traditions and neo-shamanism. In: Micozzi MS. Fundamentals of Complementary and Alternative Medicine, 5th ed. St. Louis: Elsevier Saunders; 2015:667-673.

29. Harner M. Shamanism and states of consciousness. In: The Way of the Shaman, 3rd ed. San Francisco: Harper \& Row; 1990:81-107.

30. Harner M. Introduction. In: The Way of the Shaman, 3rd ed. San Francisco: Harper \& Row; 1990:12-22.

31. Eliade M. General considerations: Recruiting methods: Shamanism and mystical vocation. In: Shamanism: Archaic Technique of Ecstasy [Bolingen Series LXXVI]. Princeton, NJ. Princeton University Press; 1964:3-32.

32. Voss RW, Moerman DE, Micozzi MS. Native North American Healing and Herbal Remedies. In: Micozzi MS. Fundamentals of Complementary and Alternative Medicine, 5th ed. St. Louis: Elsevier Saunders; 2015:623-638.

33. Lee R, Balick MJ. Chocolate: Healing 'Food of the Gods'? Altern Ther Health Med. 2001;7(5):120-122.

34. Trotter RT, Micozzi MS. Latin American curanderismo. In: Micozzi MS. Fundamentals of Complementary and Alterative Medicine, 5th ed. St. Louis: Elsevier Saunders; 2015: 667-673.

35. Jonas W, Deuster P, O'Connor F, Macedonia C. Total Force Fitness for the 21st Century: A New Paradigm. Mil Med. 2010;175(suppl):1-126.

36. Hufford DJ, Fritts MJ, Rhodes JE. Spiritual fitness. Mil Med. 2010;175:(suppl):73-87.

37. Wong KC, Wu L-T. Chinese Medicine Series 6. History of Chinese Medicine, 2nd ed. Taipei: Southern Materials Center, Inc. 1985:162-163.

Address correspondence to:

Richard P. Petri, Jr., MD, FAAPMR, FAAIM, COL MC United States Army

NATO HFM-195 Task Force

Integrative Medicine Interventions for Military Personnel 5005 North Piedras Street El Paso, TX 79920

E-mail: richard.p.petri.mil@mail.mil; richard@petrijr.com 